\section{Thalassemia and the heartquake}

Caterina Borgna-Pignatti, ${ }^{1}$

Anna Tarocco, ${ }^{1}$ Alessandro Baldan, ${ }^{1}$

Alessandro Fucili

${ }^{1}$ Department of Medical Sciences -

Pediatrics, University of Ferrara;

${ }^{2}$ Department of Emergency Medicine -

Cardiology, University of Ferrara, Italy

\section{Abstract}

On May 2012 the city of Ferrara and the surrounding region were hit by several earthquakes. We had the chance to observe the behavior of one thalassemic heart during the shocks, because of a 24-h electrocardiogram recording had been put in place a few hours before the shocks.

\section{Thalassemic heart and earth- quake}

On May 20, 2012 and again on May 29, 2012 the cities of Ferrara, Mantua and Modena and the surrounding areas were hit by several earthquakes of a maximum Richter magnitude of 5.9, followed by aftershocks lasting several days. The consequences were disastrous, with 26 deaths, 1500 people remaining without a home, commercial activities annihilated and the artistic heritage severely damaged (Figure 1). Two of the cities involved are in the UNESCO list of World Heritage. In the area hit by the earthquakes, thalassemia is prevalent, both in the intermedia and major forms. The heart of these patients with age can develop, arrhythmias pulmonary hypertension, and cardiac failure secondary to anemia or to iron overload.

We had the chance to observe the behavior of one thalassemic heart during two shocks and several aftershocks of the earthquake. The patient is a 60-year old man with thalassemia intermedia who during his lifetime received only sporadic blood transfusions, but, nevertheless, accumulated liver and heart iron. A heart biopsy, performed elsewhere in 1992, was judged to show severe overload and the patient was treated with deferoxamine via an indwelling catheter. More recently, at our center, in 2010, he underwent magnetic resonance imaging which revealed a $\mathrm{T} 2 *$ of the interventricular septum of $32 \mathrm{~ms}$ (normal value $>20$ $\mathrm{ms})$ and mild liver accumulation (2.2 ms). However myocardial scarring, a condition that facilitates arrhythmias in thalassemia patients, was suggested by delayed enhancement. ${ }^{1}$ Despite a satisfactory hemoglobin, ranging from 9 to $10 \mathrm{~g} / \mathrm{dL}$, the patient's ferritin
Correspondence: Caterina Borgna-Pignatti, Department of Medical Sciences - Pediatrics, University of Ferrara, via Aldo Moro 8, 44124 Ferrara, Italy.

Tel. +39.053.2237343 - Mobile: +39.349 .2846151 .

E-mail: bre@unife.it

Key words: thalassemia, arrhythmias, iron over load, earthquake.

Acknowledgements: we wish to thank Dr. Andrea Bono from the National Institute of Geophysics and Volcanology National Earthquakes Center for providing the tracings of the shocks and Ms. Carolina Paltrinieri for the pictures.

Contributions: CB-P, AT, AB wrote the paper AF described the cardiological aspects of the case.

Received for publication: 23 September 2013. Accepted for publication: 11 February 2014.

This work is licensed under a Creative Commons Attribution 3.0 License (by-nc 3.0).

(C) Copyright C. Borgna-Pignatti et al., 2014

Licensee PAGEPress, Italy

Thalassemia Reports 2014; 4:1941

doi:10.4081/thal.2014.1941

tended to increase. When it averaged 1200 $\mu \mathrm{g} / \mathrm{dL}$ chelation was given, until a ferritin level of $500 \mu \mathrm{g} / \mathrm{dL}$ was obtained. The patient is also affected by precapillary pulmonary hypertension that is being treated with Bosentan.

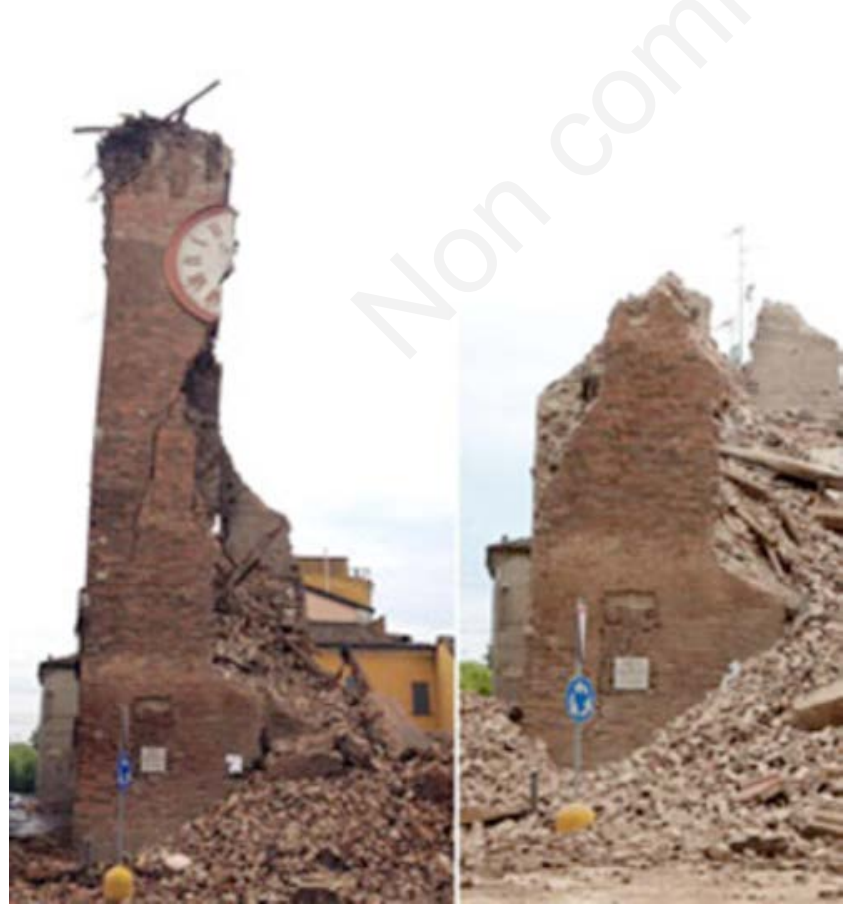

Figure 1 . The consequences of the earthquake.

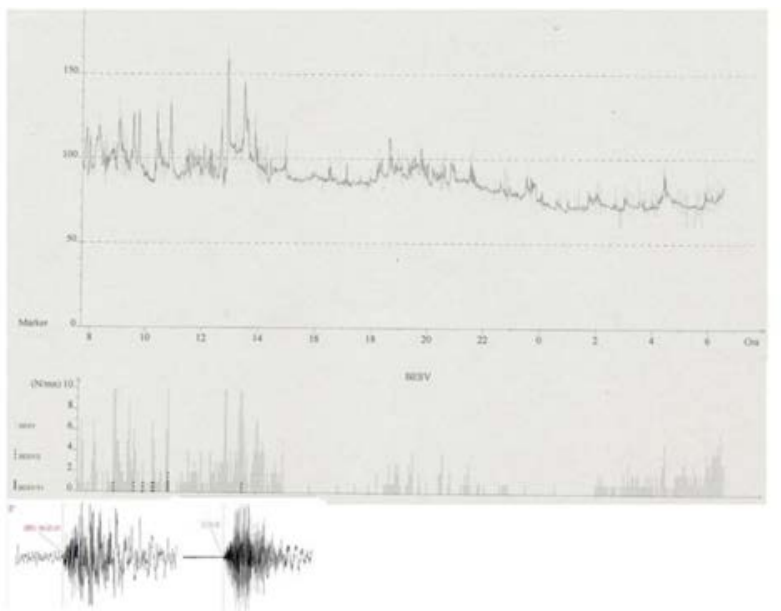

Figure 2. Recordings (below) of the vertical component of two shocks of the earthquake that hit on May 29 and that was felt by the patient. The time of the shock is expressed as coordinated universal time, i.e. the international time standard, corresponding, in Italy, to $\mathbf{2} \mathrm{h}$ later. The Holter recording (above) documented an increase in mean heart rate during the period of the earthquake. Also a temporal correlation between the aftershocks and the presence of numerous supraventricular premature contractions was observed, which increased from $1 / 2$ to $4 / 6$ per hour as an effect of the patient's anxiety and the irritability of his atrial substrate. 
During the last few weeks he had been complaining of lost beats. A 24-h electrocardiogram recording was therefore put in place on the morning of May 29 a few hours before the earthquake struck (Figure 2).

We observed that a severely traumatic natural event unleashed, as expected, tachycardia, but also increased the supraventricular prema- ture contractions, that are facilitated by heart iron overload and by myocardial fibrosis. ${ }^{1}$

We wish also to remind the entire scientific community of the tragedy that has hit a beautiful land, full of historic and artistic landmarks and generated much human suffering.

\section{Reference}

1. Pepe A, Positano V, Capra M, et al. Myocardial scarring by delayed enhancement cardiovascular magnetic resonance in thalassaemia major. Heart 2009;95: 1688-93. 